\title{
Fatality from Road Traffic Accident in Guinea: A Retrospective Descriptive Analysis
}

\author{
Keita Mamady1*, Bin Zou², Sylla Mafoule², Jiabi Qin1, Keita Hawa³ ${ }^{3}$ Keita Fodé Lamine, \\ Guoqing Hu${ }^{1}$ \\ ${ }^{1}$ Department of Epidemiology and Health Statistics, School of Public Health, Central South University, Changsha, \\ China \\ ${ }^{2}$ School of Geosciences and Info-Physics, Central South University, Changsha, China \\ ${ }^{3}$ School of Business, Central South University, Changsha, China \\ Email: "kethmohawassdeh@gmail.com
}

Received 6 September 2014; revised 8 October 2014; accepted 1 November 2014

Academic Editor: Fen Peng, The Hong Kong Polytechnic University, China

Copyright (C 2014 by authors and Scientific Research Publishing Inc.

This work is licensed under the Creative Commons Attribution International License (CC BY).

http://creativecommons.org/licenses/by/4.0/

\section{(c) () Open Access}

\section{Abstract}

Objectives: Causes and risk factors that result in fatal road traffic accident have not been described at the national level in Guinea yet. The goal of this study is to explore the causes and risk factors related to fatal road traffic accident, identified most vulnerable road users, and inform the road traffic prevention policy in Guinea. Methods: We made a retrospective descriptive analysis based on national fatal road traffic accident data from the Department of Health Information at the Guinean Ministry of Health for year 2011. Results: In 2011, road traffic accident was responsible for an aggregate number of 1655 deaths with an overall death rate of 15.3 per 100,000 population. Male experienced more than twice the risk of death from road traffic accidents $(21.9$ deaths per 100,000 population) compared with female ( 9.0 deaths per 100,000 population). While taking the population as a whole, the highest death rate was found among the middle aged in 35 - 49 age group accounting for ( 29.7 deaths per 100,000 population), followed successively by young adults age group 25 - 34 years (24.6 deaths per 100,000 population), and the middle aged in 50 - 64 age group (22.9 deaths per 100,000 population). Principally, occupants, motorcyclists and pedestrians sustained considerable burden of deaths respectively $(9.2 ; 2.9 ; 2.2$ per 100,000 population). In regional setting, the highest death rate was found in Upper Guinea (19.5 per 100,000 population), followed by Forest Guinea (18.7 per 100,000 population) and Middle Guinea (16.8 per 100,000 population). A large proportion of male was killed as motorcyclist than female while high percen-

\footnotetext{
*Corresponding author.
}

How to cite this paper: Mamady, K., Zou, B., Mafoule, S., Qin, J.B., Hawa, K., Lamine, K.F. and Hu, G.Q. (2014) Fatality from Road Traffic Accident in Guinea: A Retrospective Descriptive Analysis. Open Journal of Preventive Medicine, 4, 809-821. http://dx.doi.org/10.4236/ojpm.2014.411091 
tage of female died as occupant than male for all age group. The regional distribution showed that when a remarkable number of occupant death were observed in Upper and Forest Guinea, more people died as pedestrian and pedal cyclist in Conakry. Conclusions: This study demonstrated that most of the deaths were among occupants, motorcyclists and pedestrians, and the productive workforce aged 25 - 49 years. It was found that majority of the deaths happened in Upper Guinea followed by Forest Guinea. Improvement of roads design, strict enforcement of road safety laws and raising the awareness of general public about the causes and risks factors of road traffic accident through various channels are highly required which will promote economic growth in the local communities and then help people escape the poverty trap.

\section{Keywords}

\section{Road Traffic Accident, Fatality, Causes, Risk Factors, Guinea}

\section{Introduction}

Road traffic accident has the distinction of being one of the causes of injury that has been studied in more detail than most other causes [1]-[4] since the production of the first authoritative report on its aftereffects by the World Health Organization (WHO) more than 40 years ago [5], that is because amongst all traffic accidents, road traffic accidents claim the largest toll of human life and tend to be the most serious problem world over. Nevertheless, implementation of road traffic accident prevention programs has been slow or nonexistent in many countries around the world [5] [6].

Admittedly, it is estimated that globally over 1.2 million people die and up to 50 million are injured every year with a global mortality rate of 19 per 100,000 in 2002. Road traffic accident is the 11th leading cause of deaths and the ninth leading cause of disability-adjusted life-year lost worldwide [7]. The World Health Organization projected that road traffic accident death will be on increase of $67 \%$ by the end of 2020 if appropriate action is not taken [8] [9]. The road traffic accident burden is disproportionally distributed, with $90 \%$ of deaths occurring in low and middle income countries [8] [10] where less than half of the world's motor vehicles are owned [9].

Essentially, a previous work reported that a large proportion of the relatives of dead and disabled victims of road traffic accident, as well as the disabled themselves, suffer psychological disorders, including anxiety attacks (46\%) and suicidal feelings (37\%). Even after 3 years, these symptoms continued in most of the cases, indicating long-term and in certain cases even permanent suffering. With the exception of suicidal feelings, the relatives of disabled victims present a similar pattern to that of the relatives of dead victims [11]. On top of that, when these road accident deaths occur in healthy children who might have been expected to have had productive lives, the parents and other parties involved become immeasurably distressed and guilty, leading to lifelong social and psychological burden [12].

Then again, the total annual costs of road crashes to low-income and middle-income countries are estimated to be about US $\$ 100$ billion, which is twofold in amount of all the development assistance these countries receive from the donor states [13]. Ultimately, the economic consequences of road traffic injuries also include costs of prolonged medical care, loss of family breadwinner and loss of income due to disability, which together often push families into poverty [14].

From 1993 to 1997, the casualty department in the teaching hospital of Donka in Conakry kept on the record of 1023 deaths from all causes. The largest proportion of deaths (84\%) was attributable to road traffic accident [15]. In 2007, road traffic accident was the first leading causes of fatal injuries, with an incident rate of 27.2 per 100,000 population [16].

Since Guinea is confronted with significant human resource challenges for many decades, the country positioning in the low human development category of 178 out of 187 countries and territories for 2012, and it has never been able to emerge from the block of the last 15 countries since the inception of the global Human Development Report [17] [18], whatever losses would be of critical importance at this current level of the country's development. Therefore, identifying areas where there is potential for intervention in order to reduce mortalities due to road traffic accidents should be the most important priorities for the government and health care system 
in particular [19]. If such safety measures are executed in a short-term, the result will inevitably revive the country's struggling economy.

First of its kind, the goal of this study is to describe the causes and risk factors related to fatal road traffic accident, identified the most vulnerable road users, and inform the road traffic prevention policy in Guinea.

\section{Methods}

\subsection{Setting}

Guinea enjoys rich natural resources due to its soils, the diversity of its landscape, and its surroundings. Located on the west coast of West Africa, the Republic of Guinea shares its borders with six other countries: Côte d'Ivoire, Guinea-Bissau, Liberia, Mali, Senegal and Sierra Leone.

With an area of $245,857 \mathrm{~km}^{2}$, the country is divided into four distinct natural regions:

1) Lower Guinea, with an area of approximately $47,513 \mathrm{~km}^{2}$, has $300 \mathrm{~km}$ of coastline and covers a wide area of 100 to $150 \mathrm{~km}$ of coastal strip, which includes formations of mangroves, a set of continental lowlands, and plateaus formed of foothills on the west side of the Fouta Djallon region. The region is crossed by many rivers and receives more than $2000 \mathrm{~mm}$ of rain per year, reaching a maximum of $4000 \mathrm{~mm}$ in Conakry.

2) Forest Guinea, at $45,958 \mathrm{~km}^{2}$, has a rugged terrain, which rises to 1752 meters at the level of the Mount Nimba. As its name suggests, this region is abundantly covered by forest and has a climate characterized by a long rainy season, which ranges from seven to nine months, and an average annual rainfall of $2500 \mathrm{~mm}$.

3) Middle Guinea, which covers about $52,939 \mathrm{~km}^{2}$, is the most mountainous region of the country. Its altitude is between 750 and 1400 meters. The region has an annual rainfall ranging between $1300 \mathrm{~mm}$ in the north and slightly more than $2000 \mathrm{~mm}$ in the south.

4) Upper Guinea, meanwhile, has an area of $99,426 \mathrm{~km}^{2}$ with an average altitude of 500 meters. It is characterized by subdued topography, resulting in a dense network of rivers and abundance of floodplains. Its rainfall varies between $1200 \mathrm{~mm}$ and $1600 \mathrm{~mm}$ south to north.

\subsection{Data}

In this paper, we made a retrospective descriptive analysis based on national fatal road traffic accident data from the department of Health Information at the Guinean Ministry of Health. The study was conducted during the period from 1 January 2011 to 31 December 2011.

The data on road traffic accident deaths were collected in four natural regions namely Lower Guinea, Forest Guinea, Upper Guinea, and Middle Guinea based on Guinean Community Health Surveillance System. That system consists of a network of disease and injury surveillance system involving Hospital Discharge Register, Hospital Mortuary and City Council Mortuary data. As road traffic accidents are a part of the non-natural causes of death, these deaths are subject to medico-legal investigation and an autopsy is performed to establish the cause of death. The causes of death categories are based on the country's death notification form which has been converted into the International Classification of Diseases, ninth revision (ICD-9).

The underlying cause of death is derived manually by doctors and trained nurses. Information collected included personal demographics, detail post mortem examination findings, type of road user, nature of injury, cause of death. The nationwide data collected from these three data sources are transmitted to the Ministry of Public Health by administrative hierarchical ladder where any existing discrepancy is corrected. The data are then merged, normalized, and finally maintained as a national fatal injury database for a potential use [20]. The Ministry of Public Health of Guinea made the data easily accessible to the interested public in a form of hard or electronic copy and can be obtained by contacting the assigned officials at

http://www.stat-guinee.org/nada/index.php/catalog/1/accesspolicy/. Guinea's population was estimated to be 10,818,319 inhabitants in 2011, on the basis of the 1996 General Population and Habitat Census (GPHC). Conakry has an estimated population of (1,705,728 inhabitants), Lower Guinea (2,678,496 inhabitants), Forest Guinea (1,701,444 inhabitants), Upper Guinea (2,966,915 inhabitants), and Middle Guinea (1,765,736 inhabitants) [20] [21].

\subsection{Conceptualization of Some Key Concepts for the Purpose of This Study}

For the purpose of study, a road traffic accident was defined as any vehicle accident occurring on a public road 
or highway and which takes place between two or more objects, one of which had to be any kind of a moving vehicle. A vehicle is defined as any mechanically or electrically powered device not operated on rails and includes cars, buses, trucks, vans, motorcycles and bicycles. An occupant may be the driver operating or the passenger being carried in any mechanically or electrically powered vehicle. A motorcyclist is any person operating or being carried on a two-wheeled mechanically or electrically powered vehicle.

A bicyclist is a person riding or being carried on any vehicle operated solely by pedals. A pedestrian is a person traveling on foot. A victim of fatal road accident is anyone who is killed outright or within 30 days after the accident as recommended by WHO [10], which could include occupant, motorcyclist, pedestrians, cyclists or other road users.

\subsection{Analysis}

This study utilized the fatality rates to evaluate the magnitude of road traffic accident death among road users in Guinea, in 2011. The fatality rates were computed by dividing the number of deaths by the population size $\times$ 100,000 . Likewise, we formed an estimate of the proportion of road traffic accident death as the number of deaths characteristic to each specific demographic divided by the total deaths $\times 100$. This information is used to select, monitor and evaluate health interventions [22].

To provide a relative measure of the effect of the current national road users' protection strategy, we computed the incidence rate ratio. That incidence rate ratio was derived as the incidence rate for group of primary interest divided by the incidence rate for comparison group or reference group. We selected as a comparison group, the well specified group having smallest count of fatal road traffic accident death. A p value $<0.05$ was selected as the statistical significance level. We displayed the sex-, age-, road user-, and region-specific death rates in order to identify characteristics that require considerable policy priority. The number of road traffic death was purposely structured into 6 major age groups to reflect deaths among children (0 - 14), youth (15 - 24), young adults (25 - 34), the middle aged (35 - 49; 50 - 64) and the elderly (65 years and above). The type of road users consisted of occupant, motorcyclist, pedal cyclist, pedestrian and unspecified. The territory of Guinea is composed of four distinct natural regions namely Lower Guinea including the capital city, Conakry, Forest Guinea, Middle Guinea and Upper Guinea. For this study, the Lower Guinea and the capital city, Conakry, also called special zone have been split into two separated zones or regions.

\section{Results}

Table 1 arrays that in 2011 road traffic accident was responsible for an aggregate number of 1655 deaths, with an overall death rate of 15 per 100,000 population. Males experienced more than twice the risk of death from road traffic accidents (21.9 deaths per 100,000 population) compare with females (9.0 deaths per 100,000 population). While taking the population as a whole, the highest death rate was found among the middle aged in 35 49 age group accounting for (29.7 deaths per 100,000 population), followed successively by young adults age group 25 - 34 years (24.6 deaths per 100,000 population), and the middle aged in 50 - 64 age group (22.9 deaths per 100,000 population). The elderly aged 65-plus years, youth in 15 - 24 age group and $0-14$ years old children respectively had the death rates of (20.1 deaths per 100,000 population), (19.1 deaths per 100,000 population), and (5.5 deaths per 100,000 population).

Table 1 also depicts the road traffic accident death among the road users. Principally, occupants were obviously 14.4 times more often to die as a result of road traffic accident (9.2 deaths per 100,000 population) than the remaining road users. Occupants were by far respectively followed by motorcyclists ( 2.9 deaths per 100,000 population), pedestrians (2.2 deaths per 100,000 population), and pedal cyclists ( 0.6 death per 100,000 population).

When still scanning Table 1, people in Upper Guinea emerged to be 2 times more likely to die from road traffic accident (19.5 deaths per 100,000 population) than people in the remaining regions. Forest Guinea that took the second place was 1.9 time more likely to die from road traffic accident (18.7 deaths per 100,000 population), followed by Middle Guinea that was 1.7 times as likely to die from road traffic accident (16.8 deaths per 100,000 population). Lower Guinea and the capital city, Conakry respectively recorded the lowest death rates (11.0 deaths per 100,000 population) and (9.7 deaths per 100,000 population).

Figure 1 illustrates the proportion of road users died from road traffic accident by sex and by age group. Concerning males, the results confirm the highest proportion of occupants deaths in people aged 25 - 34, 
Table 1. Road traffic accident fatality in Guinea, 2011.

\begin{tabular}{|c|c|c|c|}
\hline Demographics & Number of deaths (\%) & Mortality/100,000 population & Mortality rate ratio $(95 \% \mathrm{CI})$ \\
\hline Total & 1655 (100\%) & 15.3 & \\
\hline \multicolumn{4}{|l|}{ Sex } \\
\hline Male & 1155 (69.8\%) & 21.9 & $2.4(2.2,2.7)^{*}$ \\
\hline Female & $500(30.2 \%)$ & 9.0 & Reference \\
\hline \multicolumn{4}{|l|}{ Age group } \\
\hline $0-14$ & 270 (16.3\%) & 5.5 & $0.3(0.2,0.3)^{*}$ \\
\hline $15-24$ & 340 (20.5\%) & 19.1 & $0.9(0.8,1.2)$ \\
\hline $25-34$ & $364(22.0 \%)$ & 24.6 & $1.2(1.0,1.5)^{*}$ \\
\hline $35-49$ & $408(24.7 \%)$ & 29.7 & $1.5(1.2,1.9)^{*}$ \\
\hline $50-64$ & $172(10.4 \%)$ & 22.9 & $1.1(0.9,1.5)$ \\
\hline $65+$ & $101(6.1 \%)$ & 20.1 & Reference \\
\hline \multicolumn{4}{|l|}{ Type of road user } \\
\hline Occupant & $993(60.0 \%)$ & 9.2 & $14.4(11.3,18.6)^{*}$ \\
\hline Motorcyclist & $311(18.8 \%)$ & 2.9 & $4.5(3.5,5.9)^{*}$ \\
\hline Pedal cyclist & $69(4.2 \%)$ & 0.6 & Reference \\
\hline Pedestrian & 234 (14.1\%) & 2.2 & $4.8(3.7,6.4)^{*}$ \\
\hline Unspecified & 48 (2.9\%) & 0.4 & $0.7(0.5,1.0)$ \\
\hline \multicolumn{4}{|l|}{ Regions } \\
\hline Conakry & $165(10.0 \%)$ & 9.7 & Reference \\
\hline Lower Guinea & $195(17.8 \%)$ & 11.0 & $1.1(0.9,1.4)$ \\
\hline Forest Guinea & 319 (19.3\%) & 18.7 & $1.9(1.6,2.5)^{*}$ \\
\hline Upper Guinea & $580(35.0 \%)$ & 19.5 & $2.0(1.7,2.4)^{*}$ \\
\hline Middle Guinea & $296(17.9 \%)$ & 16.8 & $1.7(1.4,2.1)^{*}$ \\
\hline
\end{tabular}

${ }^{*} \mathrm{p}<0.05$.

followed respectively by 50 - 64 years and 15 - 24 years. The proportion of people killed who were motorcyclist is the largest among those aged 15 - 24 years followed respectively by 35 - 49 years, and 25 - 34 . A significant proportion of bicyclists who departed from life were found in 0 - 14 years. The proportion of people killed who were pedestrians was the largest in this age group 65-plus followed by 0 - 14 years (Figure 1 ).

With respect to females, a considerable proportion of occupants deaths were observed in all age groups, with the highest in people aged 35 - 49 years and the lowest in children less than 15 years. People aged 15 - 24 made up the largest proportion of motorcyclist's deaths, followed respectively by people aged 35 - 49 years and 25 34 years. A remarkable proportion of death as pedestrians was in 65-plus, followed by the age group 50 - 64 years and children less than 15 years (Figure 1 ).

A large proportion of males were killed as motorcyclists than females and a high percentage of females died as occupants than males for all age groups. While taking in account a special risk among children, more males aged 0 - 14 years died as pedestrians and pedal cyclists than females counterparts (Figure 1).

As far as the distribution of road user's deaths by region is concerned, the most significant proportion of occupant's deaths occurred in Upper Guinea, slightly followed by Forest Guinea and Lower Guinea. The lowest proportion of death was respectively found in Middle Guinea and Conakry. Upper Guinea is also the region where the largest proportion of Motorcyclist's deaths took place followed by Forest Guinea and Middle Guinea. The most considerable proportion of deaths of pedestrians occurred in Conakry, followed by Lower Guinea. Conakry also made up the highest proportion of pedal cyclists deaths (Figure 2). 


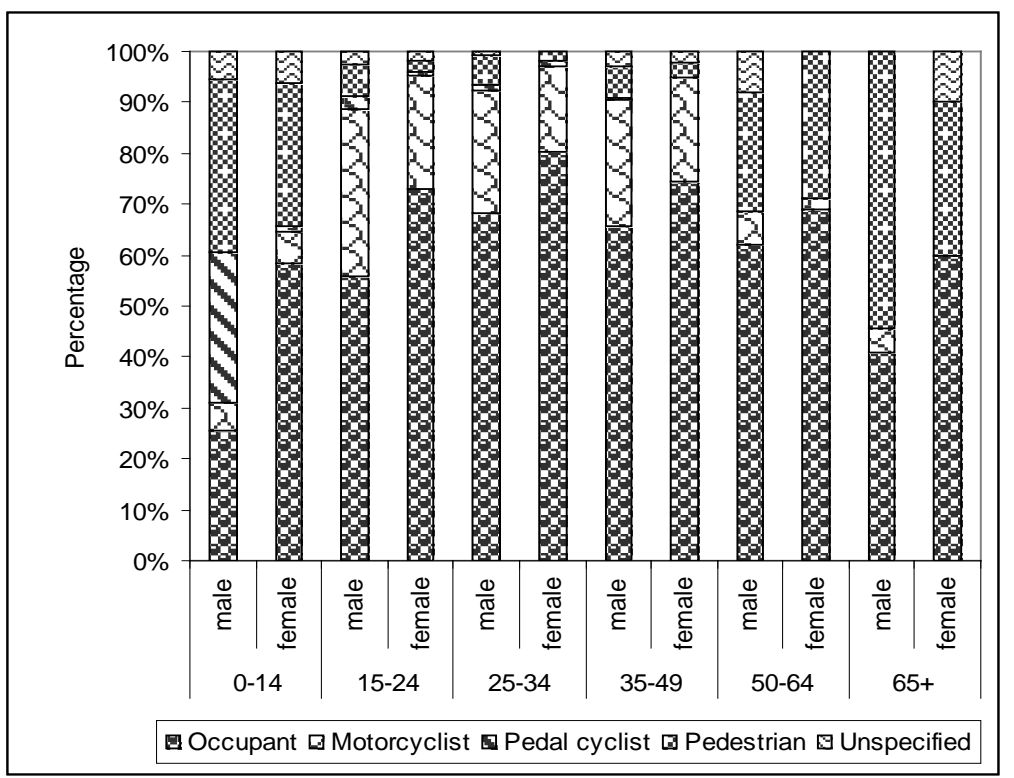

Figure 1. Percentage of the causes of road traffic accident fatality by age group (Guinea, 2011).

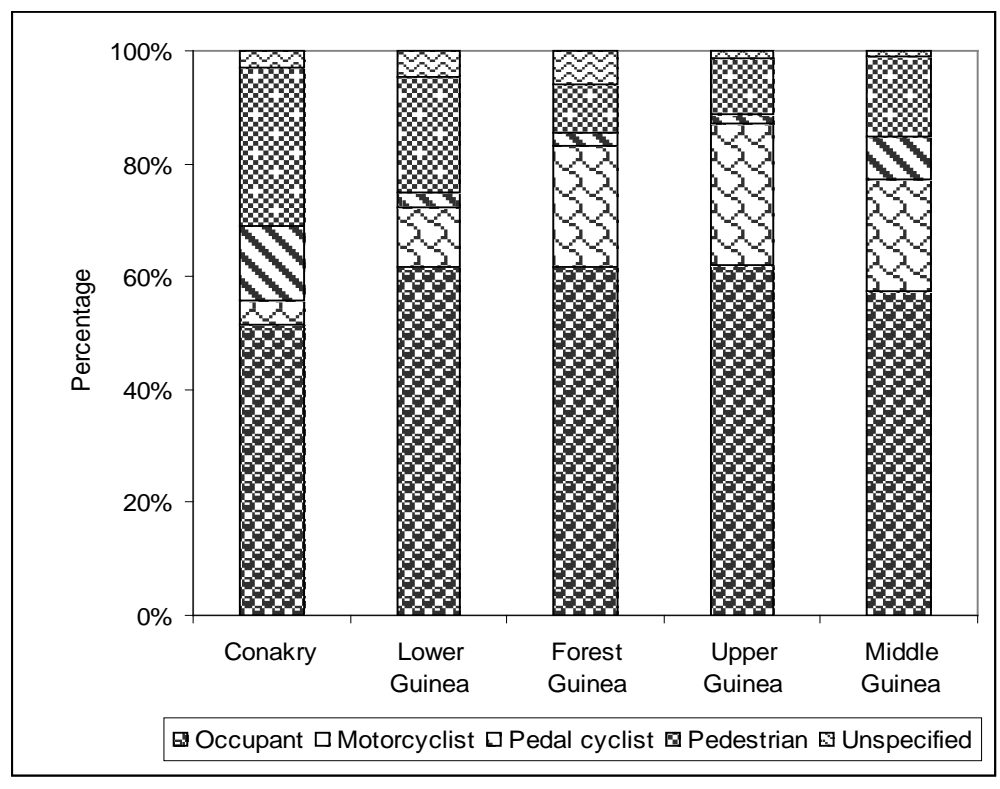

Figure 2. Percentage of the causes of road traffic accident fatality by region (Guinea, 2011).

\section{Discussions}

This current study highlighted the effects of road traffic accident on susceptible road users in term of fatality. The identification of the causes of fatality from road traffic accident will act as a sound rational argument to provide concerned moral authority for road traffic accident prevention policy in Guinea.

In this study, the road traffic death rate was 15.3 per 100,000 population overall, down from the WHO road traffic accident fatalities figure estimated for Guinea in 2010, at 19.6 per 100,000 population. The discrepancy between the death rates reported in this study and that from WHO figure might be explained by the difference in data collection methodology and the year of research. However, the annual road traffic fatality rates in developed nations based on the same estimates from WHO is lower, at 11.6 per 100,000 population, 4.8 per 100,000 
population, and 3.5 per population, respectively for the United States of America, Japan, and the United Kingdom [23].

Developed nations have simultaneously witnessed decreasing road traffic death rates for several decades now. Much of the progress in developed nations is attributable to the combination of interventions, strategies, and policies that have been developed mainly in these high-income settings over the past few decades. Such factors as high health budgets, adequate numbers of researchers, high levels of health and safety awareness, and near universal literacy, have catalyzed this progress [24] [25]. In many LICs, like Guinea, the biggest hurdles to the implementation of such strategies are the results of corruption, political instability, incompetence, cultural beliefs that injuries are acts of God, absence of clear specific structural strategic planning and policymaking of traffic accidents in the country, and competing health problems which devote serious attention to the infectious disease prevention strategies to the problem of traffic injury intervention [26] [27].

In this paper, males' deaths from road traffic accident significantly outnumbered females with the ratio of 2.4 to 1 . Previous researchers had also experienced that the majority of the deceased were males [28]-[30]. That might correspond not only to differences in the extent of greater exposure to driving, the number of trips, the choice of mode of transport, patterns of high risk-taking behaviors when driving, the acceptance of risk and a disregard of pain and injury on the part of men, but also might depend on cultural factors [31]-[33]. To consistently justify the above reasons for why the highest death rate was found among males in the context of Guinea as well as many Sub-Saharan Africa, males have an only cultural challenge which is to meet the financial needs of the family. In case of any failure to fulfill that function as the prime breadwinner will bring shame on the family, causing males to participate in various social and economic activities involving higher degrees of movement and travel. Therefore, the resulting social pressure, stress, and enormous amount of work often performed in haste may be factors leading to hazardous actions [20].

Taking account of the general population, people aged 15 - 49 years dominated the tabulations of deaths, $65.5 \%$ of fatalities from road traffic accident. This might be either linked to their patterns of motor vehicle use or the extent of higher exposure to socioeconomic activities that require being in the traffic environment. In addition, many young people in this group participate in risk taking behavior, such as speeding and drink-driving. Most importantly, factors such as high adult illiteracy, income level, job category such as sanitation workers, bus or truck drivers and road cleaners, and an increased incidence of poverty in Guinea might have, in fact, exacerbated the risk of fatal road traffic accident in that age category [34] [35]. In an article published in the latest edition of Allianz Risk Pulse Jörg Kubitzki of the Allianz Center for Technology examines the close connection between traffic safety and wealth in a society. According to Kubitzki, per capita income is a key factor in determining the likelihood of dying in a road traffic accident. Moreover, in the US National Health Interview Survey, motor vehicle deaths in a broad age range were associated with neighborhood poverty, low income, blue collar occupation, and low education [36].

This study also revealed key sex-age-related differences in exposure to fatal road traffic accident. While a large number of males aged between 15 - 49 years died as motorcyclists, many more females died as occupants may suggest societal complexity of the sexual division of labor. Societal complexity has often been mentioned as a cause of variation in the sexual division of labor. For example, in the case of Guinea, professional or commercial driving might become occupational specialty tasks in complex societies with the consequence that they are done by males rather than females, when female's activities tend to be focused on less risky activity such as the processing activities [37]. On top of that, another recent study from the US reports that for age 20 - 35 years, females occupants of motor vehicles were $28 \%$ - $31 \%$ more likely to die than males from similar crash forces, because of their smaller body stature [33].

A vast majority of people aged 50-plus and children less than 15 years males and females died as pedestrians, most of those deaths occurred in Conakry. That may be explained by urban sprawl setting [38]. And also, in Conakry, walking is by far the chief means of transport, and more so among the poor. Travel on foot is usually under harsh conditions, not to mention the discomfort always involved in walking during difficult weather conditions (severe heat and heavy rains). Pedestrians face two types of obstacles: lack of or insufficient roadways and sidewalks, and nuisances due mainly to the city's conditions (poor lighting, unsafe roads, filth) [39]. In Conakry, electricity is used as a source of lighting by only three out of five people [40]. If the risk for children may be the lack of appropriate parental care, for old and elderly people that might be due to age-related declines in vision, hearing, reaction time cognitive function, and physical ability increase the older people being involved in a traffic crash according to some authors [41]-[43]. 
In contrast to girl aged less than 15 , boys were more likely to die as cyclists. A similar distinct difference in the road use pattern was seen between boys and girls based on socioeconomic strata. Girls were less likely to use a cycle and were more likely to walk. This is probably because boys are given more freedom and are less restrained by the parents to move around as compared with girls. This is also reflected in the larger number and variety of cycles available for boys than for girls in Guinea and elsewhere. It is conceivable that the households with lower income are less able to afford a cycle for their children and hence the children belonging to the lower per capita household income quartile were the least likely to be making road trips using a cycle [44]. Bicycles are commonly used by laborers, school students, and pre-school children for entertainment in Guinea. As there are no dedicated bicycle lanes, the cyclists are vulnerable to injuries in rural areas due to bad, narrow roads, and sometimes domestic animals may either stand or sit on the roads, thereby obstructing the passage, when in the urban areas roads are congested and have vehicles of various speeds; such a kind of factors may possibly increase the chance of crash [45].

Our results showed that occupants were the first type of road user killed in road traffic accidents. Several factors might have been associated with a marked increase (i.e., at least 9.2 times) in the risk of occupants death such as occupant, vehicle, crash and environmental factors. It is often reported that road traffic injuries in developing countries mostly affect pedestrians, passengers, and cyclists - as opposed to drivers, in whom most of the deaths and disabilities in the developed world occur [46].

In Guinea, road transport is either dominated by second-hand vehicles imports from wealthier countries that lack up-to-date safety features or 20-plus years old passenger vehicles that tend to be older sometimes and do not have air bags, collapsible steering columns or other crash protective features. Those vehicles are poorly maintained due to poverty, ignorance and corruption among enforcement agents. Given the prominence of commercial vehicles in a sector where there is high growing competition in business operations can often cause drivers to indulge in some fairly risky behavior such as driving too fast, driving with excess loads, rest too little, stay awake using drugs or alcohol on poor road and often in bad weather conditions. Such driving behaviors might possibly end up in single-vehicle crash, head-on collision, collision with fixed object, and collision at intersection which often leads to deadly accidents [47]-[49]. Traveling with drivers suspected of being impaired by alcohol, head-on collisions, collided with a fixed object and an occupant being ejected from the vehicle might have been highly involved in occupants' deaths. Prior study proved that occupants, who were traveling with drivers suspected of driving under the influence, were 1.5 times more likely to be killed than those who were not. In Guinea, a local newspaper has already reported that in almost $36 \%$ of fatally injured drivers some quantity of alcohol was consumed prior to the collision [50]. Additionally, occupants who were involved in head-on collisions were more than twice more likely to be killed than those who were not, and occupants of vehicle that collided with a fixed object were nearly 1.5 times more likely to be killed. Then again, occupant who was ejected from the vehicle was at an increased risk of death by over 6 times than that was not [49].

To still analyze the occupant death through the risk of crash in rural setting, in most rural areas in Guinea, undeveloped traffic culture is particularly marked in some drivers. Most drivers are illiterate, poor trained, only have little information about traffic rules. Most of those drivers don't believe in the scientific explanation of the cause and prevention practice of road traffic accident, they only believe that accident is the result of ancestral anger, evil spirit or malediction, and can be prevented by wearing amulet, talisman and fetish, which magical symbols are thought to be protective against ill will, negative influences and evil spirits when involved in any daily activity. That risky believes in the protective power of supernatural may not only adversely affect decision-making ability of the drivers, but also reinforce the feelings of confidence [51] [52]. Confidence feeds itself and grows unchecked until something happens-a near-miss or an accident [53].

Another factor in Guinea that can result in accidental crash may be linked to the problem of highway bandits. Despite the advances thus noted in campaign to improve road security, the problem of highway robbers who use small arms to extort money from traders and prey upon ordinary people has been often reported in countryside. The effects of perpetrations of that phenomenon of big-time banditry are often reported to be the cause of fatal accident [54] [55].

After occupants, motorcyclists were the second type of road user killed in road traffic accidents. Per vehicle mile traveled, motorcycle riders have a 34-fold higher risk of death in a crash than people driving other types of motor vehicles [56]. Past motorcycle crash history, number of riding days, average riding distance, risk-taking level, alcohol consumption, and traffic violations were all significantly associated with an increased risk of being involved in a crash [57]. Other modifiable protective or risk factors comprise inexperience and driver train- 
ing, conspicuity and daytime headlight laws, motorcycle licensure and ownership, riding speed, and risk-taking behaviors [56]. Due to the shortage of transport supply in a number of Sub-Saharan African countries such as Guinea, the availability of factors of production and the permissiveness of the regulatory framework, motorized two-wheelers or motorbike taxi have been increasingly appropriated for a commercial activity involving male and sometimes female [58]-[60], and yet most of those motorcyclists in Guinea lack the basic traffic culture, poorly trained, run on poor roadway design, with constant road hazards creates by uncontrolled livestock which often lead to fatal accident [61].

In this study, the highest rate of death was found in Upper Guinea, while the smallest rate was found in Conakry, the capital city of Guinea. The highest rate in Upper Guinea might account for the fact that in recent years, because of the development of the mining activities, that area has been the leading magnet for many people in search for better opportunities, on the other hand the region has a great deal of vital socio-economic lifelines from where Guinea is connected to the main trading boarding countries such as the republic of Mali and Ivory Coast by road network, but that region lack drastically the specialized trauma care center, trauma care equipment as well as post-crash care services. Despite Conakry being at the same risk of massive immigration, overpopulation, higher motorization, and intense socioeconomic activities had the lowest death rate from road traffic accident. Conakry is served by two teaching hospitals both specialized in trauma care and the high availability of intensive care staff in the remaining health facilities might have reduced the poor outcome in terms of death for people involved in road traffic crashes. More than 60 percent of health personnel are concentrated in the capital city, Conakry serving only 20 percent of the country's total population [23] [62].

The data used in this study provides important information on road traffic deaths in the country, in so far as the validity, reliability and representativeness of the analyzed data are said to be assured according to the annual health statistics report. It is however important to note that the data has some limitations related to incompleteness of background information on the deceased, inadequate specification of cause of death, and under- and late registration of deaths [20]. Also, the road traffic accident death data of this study might have been underreported due to the lack of a uniform definition for road traffic death at the national level. Because of high cost of medical interventions, more and more people began to seek traditional practitioners for alternatives. Since traditional healers are not aware of evidenced based diagnosis knowledge, there is chance that the injured person dies because of conditions other than road traffic injury which may lead to misclassification. This study is also limited by the coding practice which may differ by sources of data collections resulting in a systematic bias in the road traffic accident death coding rate for a given event.

Based on the finding of this study, we formulate the following recommendations and bring them to the attention of the policy makers.

A national statutory body for prevention of road traffic accidents should be established. Reliable and sustainable injury surveillance data should be collected including secondary data routinely collected from hospital and police records, which comprises an important foundation for monitoring and evaluating road safety strategies in Guinea. Drivers should be constantly trained to ensure that they operate vehicles safely and comply with traffic regulations at all times. The single most important thing a person can do to stay healthy and alive is to pay close attention to the way he or she drives or walks. Traffic safety education should be given in schools for production of skilled and responsible drivers in future. General and sobriety checkpoints should be instituted, raising public awareness of helmet and seatbelt use through mass media campaigns, speed limit enforcement, vehicle inspections, and traffic engineering, such as better road design should be instituted [63].

In terms of emergency medical care, there should be traffic aid posts at suitable distances on the highways to assist injured in case of accidents and quick transport of injured. Policeman at such posts should be trained in first aid procedures and ambulance with paramedical staff, oxygen, and lifesaving drugs at strategic points must be ready. Hospitals along major highways should be equipped with experienced surgical team, trauma centers with integrated facility of surgical, orthopedics and neurosurgical, anesthetic experts with modern investigative procedures as Computerized Tomography Scan and Blood Banks is best solution for treatment. Modern rehabilitation measures for injured victims form an essential part of casualty service. There is no panacea that will prevent road traffic accidents, what is required is an organized teamwork by people in many disciplines like education, engineering, medical, law enforcement agencies for effective prevention of road accidents.

Prevention efforts should also consider the social context and aim to reduce inequities across socio-demographic and across geographical areas [64] [65]. Policy makers should consider interventions and campaigns targeted at groups at high risk and different traffic users. The police department security should be given more 
logistic aid to ward off the threat from highway banditry. This study finally suggests that greater efforts to reduce the burden of road traffic fatality in Guinea are in urgent need of implementation.

\section{Conclusion}

All in all, this study demonstrated that most of the deaths were among occupants, motorcyclists, pedestrians, and the productive workforce aged 25 - 49 years. It was found that majority of the death happened in Upper Guinea followed by Forest Guinea. Improvement of roads design, strict enforcement of road safety laws and raising the awareness of general public about the causes and risks factors of road traffic accident through various channels are highly required which will promote economic growth in the local communities and then help people escape the poverty trap.

\section{Acknowledgements}

The authors thank Central South University in China and the Guinean Ministry of Public Health for their contributions to this study.

\section{Conflict of Interest}

The authors have stated explicitly that there are no conflicts of interest.

\section{References}

[1] Haddon, W., Klein, D.L. and Suchman, E.A. (1965) Accident Research Methods and Approaches. Harper \& Row, New York.

[2] Roberts, H.J. (1971) The Causes, Ecology and Prevention of Traffic Accidents. Charles C. Thomas, Springfield.

[3] MacFarland, R., Moore, R.C. and Warren, A.B. (1955) Human Variables in Motor Traffic Accidents. Harvard School of Public Health, Boston.

[4] Jayasuriya, R. (1991) Trends in the Epidemiology of Injuries Due to Road Traffic Accidents in Papua New Guinea. Asia-Pacific Journal of Public Health, 5, 41-48. http://dx.doi.org/10.1177/101053959100500110

[5] Hazen, A. and Ehiri, J.E. (2006) Road Traffic Injuries: Hidden Epidemic in Less Developed Countries. Journal of the National Medical Association, 98, 73-82.

[6] Kual, A., Sinha, U.S., Pathak, Y.K., Singh, A., Kapoor, A.K., Sharma, S. and Singh, S. (2005) Fatal Road Traffic Accidents, Study of Distribution, Nature and Type of Injury. Journal of Indian Academy of Forensic Medicine, 27, 71-76.

[7] Al-Maniri, A.A.N., Al-Reesi, H. and Nasrullah, M. (2013) Road Traffic Fatalities in Oman from 1995 to 2009 : Evidence from Police Reports. International Journal Preventive Medicine, 4, 656-663.

[8] Peden, M., Scurfield, R., Sleet, D., Mohan, D., Hyder, A.A., et al. (2004) World Report on Road Traffic Injury Prevention. World Health Organization, Geneva.

[9] Parkinson, F., Kent, S., Aldous, C., Oosthuizen, G. and Clarke, D. (2013) Road Traffic Crashes in South Africa: The Burden of Injury to a Regional Trauma Centre. South African Medical Journal, 103, 850-852. http://dx.doi.org/10.7196/samj.6914

[10] WHO (2009) Global Status Report on Road Safety: Time for Action. World Health Organization, Geneva.

[11] European Transport Safety Council (2007) Social and Economic Consequences of Road Traffic Injury in Europe. Brussels. http://etsc.eu/wp-content/uploads/Social-and-economic-consequences-of-road-traffic-injury-in-Europe.pdf

[12] Singh, H. and Aggarwal, A.D. (2010) Fatal Road Traffic Accidents among Young Children. Journal of Indian Academy of Forensic Medicine, 32, 286-288.

[13] Wahid Al-Kharusi, F.R.C.S. (2008) Update on Road Traffic Crashes. Clinical Orthopaedics and Related Research, 466, 2457-2464. http://dx.doi.org/10.1007/s11999-008-0439-5

[14] Khan, M.H., Ahmed, I., Babar, T.S. and Babar, K.S. (2007) Road Traffic Accidents: Study of Risk Factors. Professional Medical Journal, 14, 323-327.

[15] Diakite, A.K., Anzilania, D. and Camara, N.D.R. (2005) Fatal Road Traffic Accident at the University Teaching Hospital of Donka. Mali Medical, 1-2, 17-19.

[16] Mamady, K., Yao, H.Y., Zhang, X.J., Xiang, H.Y., Tan, H.Z. and Hu, G.Q. (2012) The Injury Mortality Burden in Guinea. BMC Public Health, 12, 733. http://dx.doi.org/10.1186/1471-2458-12-733

[17] UNDP (2012) The Rise of the South: Human Progress in a Diverse World. Human Development Report 2013, Guinea. 
http://hdr.undp.org/sites/default/files/Country-Profiles/GIN.pdf

[18] Global Alliance for Vaccines and Immunization Alliance (2009) Health System Strengthening Support for the Republic of Guinea. Proposal for Health System Strengthening Support, CH 1202, Geneva.

[19] Vahabzadeh, E. (2005) The Effect of Human Factor on Occurring Road Accidents in Karaj-Qazvin Highway in 2005: Control for Reduction. Journal of Studies on Traffic Management, 9, 57-84.

[20] Department of National Health Information, Ministry of Public Health of Guinea (2012) Guinean Annual Health Statistics Report 2011. The Ministry of Public Health of Guinea, Conakry.

[21] Republic of Guinea (2013) Guinea Is Back and Ready for Business. Guinea’s Development Partners and Investor Conference-General/Narrative, Guinea. http://allafrica.com/download/resource/main/main/idatcs/00071477:a1d7ad5d2bcde810c04a9d87d7cb1be8.pdf

[22] The Johns Hopkins and the International Federation of Red Cross and Red Crescent Societies. Epidemiology and Surveillance. Public Health Guide for Emergencies.

http://www.jhsph.edu/research/centers-and-institutes/center-for-refugee-and-disaster-response/publications_tools/publi cations/_CRDR_ICRC_Public_Health_Guide_Book/Chapter_6_Epidemiology_and_Surveillance.pdf

[23] WHO (2013) Global Status Report on Road Safety 2013: Supporting a Decade of Action. World Health Organization (WHO), Geneva. http://www.un.org/ar/roadsafety/pdf/roadsafetyreport.pdf

[24] Bhalla, K., Shahraz, S., Bartels, D. and Abraham, J. (2009) Methods for Developing Country Level Estimates of the Incidence of Deaths and Non-Fatal Injuries from Road Traffic Crashes. International Journal of Injury Control and Safety Promotion, 16, 239-248. http://dx.doi.org/10.1080/17457300903402184

[25] Forjuoh, S.N. (2003) Traffic-Related Injury Prevention Interventions for Low-Income Countries. Injury Control and Safety Promotion, 10, 109-118. http://dx.doi.org/10.1076/icsp.10.1.109.14115

[26] Ngallaba, S.E., Makerere, D.J., Kapesa, A., Gilyoma, J. and Chalya, P. (2014) A Retrospective Study on the Unseen Epidemic of Road Traffic Injuries and Deaths Due to Accidents in Mwanza City-Tanzania. Open Journal of Preventive Medicine, 4, 222-228. http://dx.doi.org/10.4236/ojpm.2014.44028

[27] Ainy, E., Hamid, S., Mahfozphoor, S. and Movahedinejad, A.A. (2011) Presenting a Practical Model for Governmental Political Mapping on Road Traffic Injuries in Iran in 2008: A Qualitative Study. Journal of the Royal Society of Medicine Short Reports, 2, 79.

[28] Farooqui, J.M., Chavan, K.D., Bangal, R.S., Aarif Syed, M.M., Thacker, P.J., Alam, S., Sahu, S., Farooqui, A.A.J. and Kalakoti, P. (2013) Pattern of Injury in Fatal Road Traffic Accidents in a Rural Area of Western Maharashtra, India. Australasian Medical Journal, 6, 476-482. http://dx.doi.org/10.4066/AMJ.2013.1839

[29] Kyada, H.C., Mangal, H., Momin, S.G., Vijapura, M.T. and Bhuva, S.D. (2012) Profile of Fatal Road Traffic Accidents in Rajkot City. Journal of Indian Academy of Forensic Medicine, 34, 135-138.

[30] Honnungar, R.S., Aramani, S.C., Vijay Kumar, A.G., Ajay Kumar, T.S. and Jirli, P.S. (2011) An Epidemiological Survey of Fatal Road Traffic Accidents and Their Relationship with Head Injuries. Journal of Indian Academy of Forensic Medicine, 33, 135-137.

[31] Martin, J.L., Lafont, S., Chiron, M., Gadegbeku, B. and Laumon, B. (2004) Differences between Males and Females in Traffic Accident Risk in France. Revue d'Épidémiologie et de Santé Publique, 52, 357-367. http://dx.doi.org/10.1016/S0398-7620(04)99065-7

[32] Al-Balbissi, A.H. (2003) Role of Gender in Road Accidents. Traffic Injury Prevention, 4, 64-73. http://dx.doi.org/10.1080/15389580309857

[33] Gender and Health (2002) Gender and Road Traffic Injuries. http://whqlibdoc.who.int/gender/2002/a85576.pdf

[34] UNESCO Institute for Statistics (2012) Adult and Youth Literacy, 1990-2015 Analysis of Data for 41 Selected Countries. Montreal. http://www.uis.unesco.org/Education/Documents/UIS-literacy-statistics-1990-2015-en.pdf

[35] International Monetary Fund (2012) Guinea: Poverty Reduction Strategy Paper-Annual Progress Report. IMF Country Report No. 12/61, Washington DC. http://www.imf.org/external/pubs/ft/scr/2012/cr1261.pdf

[36] Allianz Risk Pulse (2012) Traffic Casualty Risks Are on the Rise. Focus: Mobility and Road Safety. http://assets.knowledge.allianz.com/downloads/allianz risk pulse mobility road safety.pdf

[37] Dow, M., White, D.R. and Hansen, D. (1981) Network Autocorrelation. Manuscript. School of Social Sciences, University of California, Irvine.

[38] Ewing, R., Shieber, R.A. and Zegger, C.V. (2003) Urban Sprawl as a Risk Factor in Motor Vehicle Occupant and Pedestrians Fatalities. American Journal of Public Health, 93, 1541-1545. http://dx.doi.org/10.2105/AJPH.93.9.1541

[39] World Bank (2004) Poverty and Urban Mobility in Conakry. Sub-Saharan Africa Transport Policy Program and International Solidarity on Transport and Research in Sub-Saharan Africa. Final Report: SSATP Report No 09/04/CKR. 
http://www.gtkp.com/assets/uploads/20091127-171237-6675-Conakry_en.pdf

[40] African Development Bank Group (2013) Project: Conakry Electricity Network Rehabilitation and Extension Project 2 (PREREC 2). Environmental and Social Management Plan. Guinea. http://www.afdb.org/fileadmin/uploads/afdb/Documents/Environmental-and-Social-Assessments/Guinea\%20-\%20Con akry\%20Electricity\%20Network\%20Rehabilitation\%20and\%20Extension\%20Project\%202\%20(PREREC\%202)\%20 \%E2\%80\%93\%20ESMP\%20Summary.pdf

[41] Chisholm, D., Naci, H., Hyder, A.A., Tran, N.T. and Peden, M. (2012) Cost-Effectiveness of Strategies to Combat Road Traffic Injuries in Sub-Saharan Africa and South East Asia: Mathematical Modeling Study. British Medical Journal, 344, e612. http://dx.doi.org/10.1136/bmj.e612

[42] Schlundt, D.G., Warren, R.C. and Miller, S. (2004) Reducing Unintentional Injuries on the Nation's Highways: A Literature Review. Journal of Health Care for the Poor and Underserved, 15, 76-98. http://dx.doi.org/10.1353/hpu.2004.0012

[43] Damsere-Derry, J., Ebel, B.E., Mock, C.N., Afukaar, F. and Donkor, P. (2010) Pedestrian’s Injury Patterns in Ghana. Accident Analysis \& Prevention, 42, 1080-1088. http://dx.doi.org/10.1016/j.aap.2009.12.016

[44] Dandona, R., Kumar, G.A., Ameratunga, S. and Dandona, L. (2011) Road Use Pattern and Risk Factors for Non-Fatal Road Traffic Injuries among Children in Urban India. Injury, 42, 97-103. http://dx.doi.org/10.1016/j.injury.2009.10.048

[45] Direction Nationale de la Statistique (DNS) and ORC Macro (2006) Demographic and Health Survey 2005: Key Findings. DNS and ORC Macro, Calverton. http://dhsprogram.com/pubs/pdf/SR116/SR116.pdf

[46] Nantulya, V.M. and Reich, M.R. (2002) The Neglected Epidemic: Road Traffic Injuries in Developing Countries. British Medical Journal, 324, 1139-1141. http://dx.doi.org/10.1136/bmj.324.7346.1139

[47] Wikipedia, the Free Encyclopedia. Guinea. http://en.wikipedia.org/wiki/Guinea

[48] AFP (2013) Road Traffic in Guinea: 50 Killed and 27 Injured. AFP News. http://www.africanewsmag.com/fichiers/videos5.php?langue=fr\&idc=fr_Grave_accident_de_la_route_en_Guin_e_50 _morts_et_27_bless_s_

[49] Singleton, M. and Qin, H.F. (2003) Risk Factors for Death or Hospitalization among Occupants of Passenger Motor Vehicles that Were Severely Damaged in Crashes in Kentucky, 2000-2001. Kentucky Injury Prevention \& Research Center, Lexington. http://www.mc.uky.edu/kiprc/projects/Codes/SNposter.pdf

[50] Sow, A. (2014) End of Ramadan Celebration: Drunk Driving and Speeding Caused Road Traffic Accident in Labé, Lower Guinea, Guinea. Guinee News.

http://guineenews.org/fete-du-ramadan-ivresse-au-volant-et-exces-de-vitesse-provoquent-des-accidents-de-circulationa-labe/

[51] Ojua, T.A., Ishor, D.G. and Ndom, P.J. (2013) African Cultural Practices and Health Implications for Nigeria Rural Development. International Review of Management and Business Research, 2, 176-183.

[52] Sanoh, S. (2014) Alpha Cop on Ébola: This Disease Is a Misfortune but Let Us Act Together in Order to Turn It into Happiness. Guinee News.

http://guineenews.org/alpha-conde-sur-ebola-cette-maladie-est-un-malheur-mais-faisons-tout-pour-quelle-soit-notre-bo nheur/

[53] The Good, the Bad and the Talented (2007) Young Drivers' Perspectives on Good Driving and Learning to Drive (Road Safety Research Report No. 74). Transport Research Laboratory.

[54] Sonomou, E. (2014) Arrest of Four Presumed Highway Bandits in Kankan. Guinee News. http://guineenews.org/des-jeunes-manifestants-reclament-la-tete-des-presumes-coupeurs-de-route-arretes-a-kankan/

[55] Xinhua (2014) Two Highway Bandits Beaten to Death by an Angry Crowd in Siguiri, Haute Guinee, Republic of Guinea. http://www.lexpressguinee.com/fichiers/blog16-999.php?langue=fr\&type=rub4\&code=calb4529

[56] Lin, M.R. and Kraus, J.F. (2009) A Review of Risk Factors and Patterns of Motorcycle Injuries. Accident Analysis \& Prevention, 41, 710-722. http://dx.doi.org/10.1016/j.aap.2009.03.010

[57] Lin, M.R., Chang, S.H., Pai, L. and Keyl, P.M. (2003) A Longitudinal Study of Risk Factors for Motorcycle Crashes among Junior College Students in Taiwan. Accident Analysis and Prevention, 35, 243-252. http://dx.doi.org/10.1016/S0001-4575(02)00002-7

[58] Olvera, L.D., Plat, D., Pochet, P. and Maïdadi, S. (2012) Motorbike Taxis in the “Transport Crisis” of West and Central African Cities. EchoGeo. http://dx.doi.org/10.4000/echogeo.13080

[59] Kumar, A. (2011) Understanding the Emerging Role of Motorcycles in African Cities. A Political Economy Perspective. Sub-Saharan Africa Transport Policy Program. SSATP Discussion Paper No. 13. Urban Transport Series.

[60] Chang, R. (2012) Kiva Innovations: Helping Motorcycle Taxis Hit the Road (It’s More Important That You Might 
Think!). http://www.kiva.org/updates/kiva/2012/11/13/kiva-innovations-helping-motorcycle.html

[61] OSAC Country Council Information (2013) Guinea 2013 Crime and Safety Report. https://www.osac.gov/pages/ContentReportPDF.aspx?cid=13769

[62] The World Bank (2006) Guinea: A Country Status Report on Health and Poverty. Working Paper Series No. 45. Africa Region Human Development, the World Bank. http://siteresources.worldbank.org/INTAFRREGTOPEDUCATION/Resources/444659-1212165766431/H_CSR_Guin ea.pdf

[63] Ditsuwan, V., Veerman, L.J., Barendregt, J.J., Bertram, M. and Vos, T. (2011) The National Burden of Road Traffic Injuries in Thailand. Population Health Metrics, 9, 2. http://dx.doi.org/10.1186/1478-7954-9-2

[64] Plasencia, A. and Borrell, C. (2001) Reducing Socioeconomic Inequalities in Road Traffic Injuries: Time for a Policy Agenda. Journal of Epidemiology and Community Health, 55, 853-854. http://dx.doi.org/10.1136/jech.55.12.853

[65] Von Elm, E. and Niemann, S. (2008) Accidents and Their Societal Consequences. In: Swiss Health Observatory, Ed., Health in Switzerland, National Health Report 2008, Verlag Hans Huber, Bern.

\section{Abbreviations}

ICD: 9th International Classification of Diseases;

WHO: World Health Organization;

LICs: Low Income Countries. 
Scientific Research Publishing (SCIRP) is one of the largest Open Access journal publishers. It is currently publishing more than 200 open access, online, peer-reviewed journals covering a wide range of academic disciplines. SCIRP serves the worldwide academic communities and contributes to the progress and application of science with its publication.

Other selected journals from SCIRP are listed as below. Submit your manuscript to us via either submit@scirp.org or Online Submission Portal.
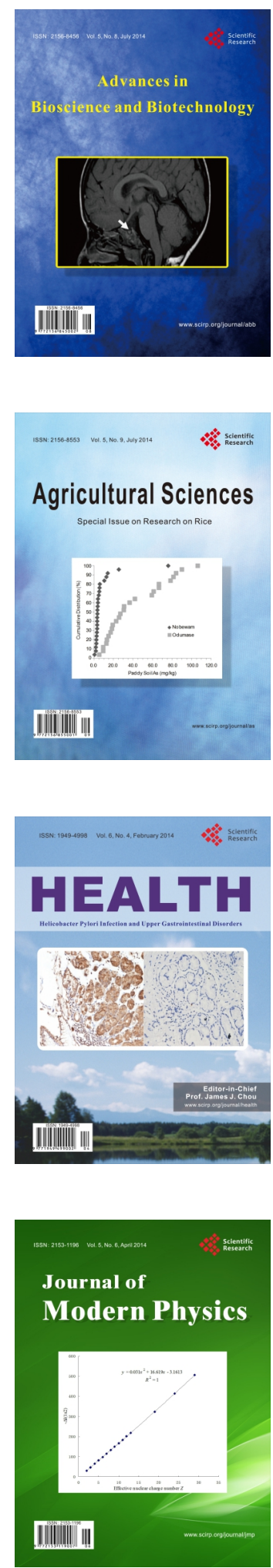
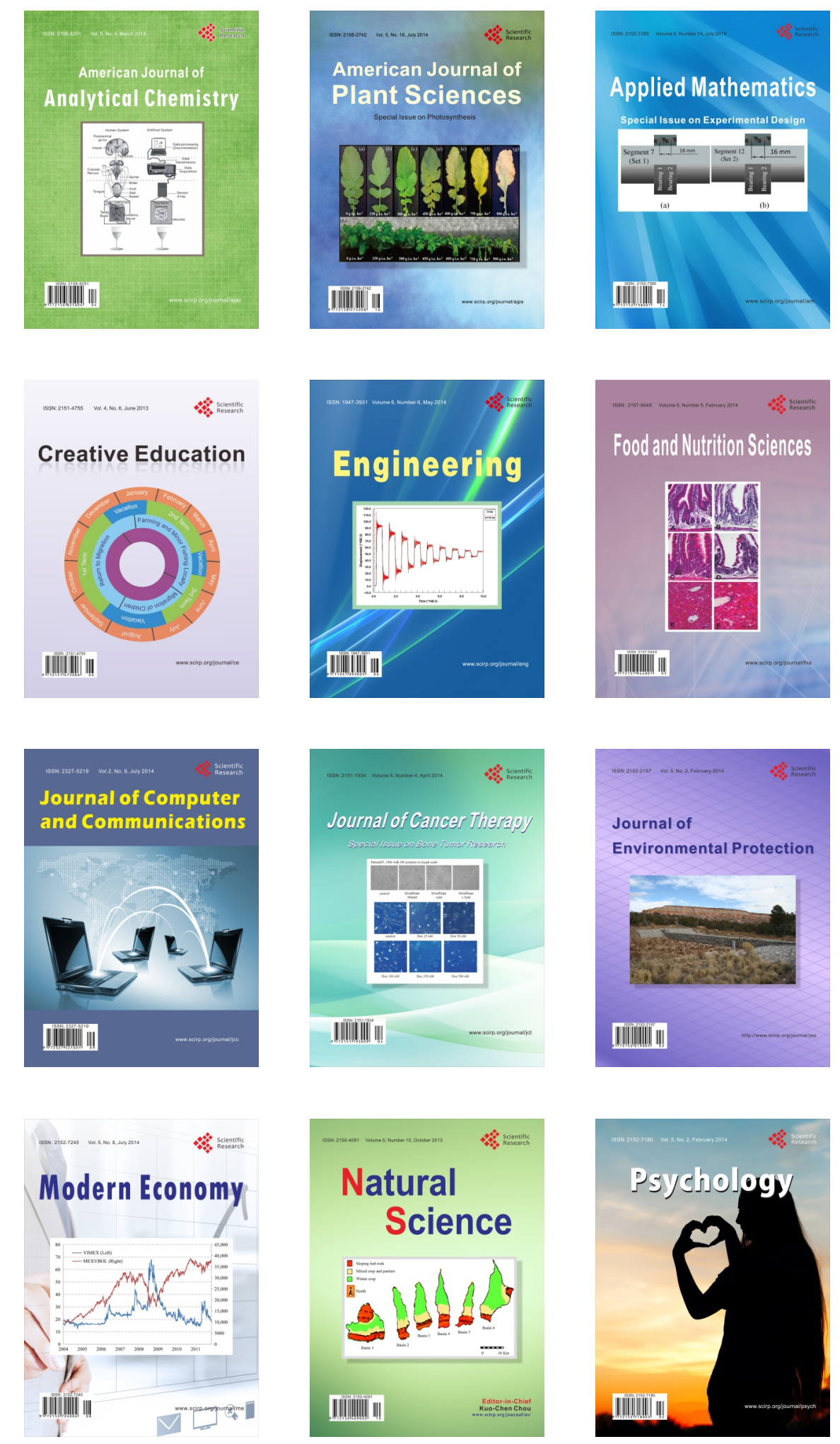